\title{
A QUALITATIVE STUDY OF YOUNG MEN WHO HAVE SEX WITH MEN AND MULTILEVEL FACTORS RELATED TO HIV RISKS IN MALAYSIA
}

\author{
William J. Burch, Graham J. Hart, and Sin How Lim
}

\begin{abstract}
Young men who have sex with men (YMSM) are a group at high risk for HIV infection, yet no research has been conducted to understand this population in Malaysia. Semistructured interviews from a combination of YMSM aged 18-25 $(n=20)$ and local service providers of sexual health services $(n=4)$ were conducted from May to June 2015. Thematic analysis was used to identify common themes in participant responses from transcripts. Participants reported societal and internalized homophobia, an absence of sex education and difficulty accessing confidential HIV testing. This study provides insights into how homophobia in Malaysian society influences individual risk behavior for HIV in Malaysian YMSM, and makes practical suggestions for more effective HIV prevention in this population.
\end{abstract}

HIV among YMSM is an emerging public health issue (Mustanski, Newcomb, Bois, Garcia, \& Grov, 2011). The available global data shows that, compared to older MSM, HIV incidence rates are consistently higher among YMSM in both high-income (Balaji et al., 2013; Beyrer et al., 2013; Stahlman et al., 2016) and middle- to lower-income countries (Stahlman et al., 2016; Vutthikraivit, Lertnimitr, Chalardsakul, Imjaijitt, \& Piyaraj, 2014). For this reason, YMSM have been identified as a priority for global HIV prevention (World Health Organization, 2015). Previous studies on YMSM in developed countries show that YMSM differ from older MSM in HIV risks, which can be explained by a host of individual, social, cultural, and structural factors (Mustanski et al., 2011). Particularly, homophobia has been found to impede access and utilization of HIV testing among YMSM (Santos et al., 2013).

William J. Burch, MBBS, BSc, and Graham J. Hart, PhD, FMedSci, are affiliated with the Faculty of Population Health Sciences, University College London, London, UK. Sin How Lim, PhD, is affiliated with the Centre of Excellence for Research in AIDS (CERiA), University of Malaya, Kuala Lumpur, Malaysia.

We are grateful to all the study participants and staff at PTF and KLASS. Special thanks to Veena Pillai, Raja Iskandar and Adeeba Kamarulzaman (CERiA), and Chongyi Wei (UCSF).

This research was supported by funding from the Faculty of Public Health, British Medical and Dental Student Trust, the Lord Mayor 800th Anniversary Trust, University College London, the Hayes (Kent) Trust, and University of Malaya High Impact Research Grant (E000001-20001). SHL was supported by an International AIDS Society-National Institute on Drug Abuse Post-Doctoral Training Fellowship.

Address correspondence to Sin How Lim, Department of Social and Preventive Medicine (SPM), Centre of Excellence for Research in AIDS (CERiA), University of Malaya, Faculty of Medicine, Kuala Lumpur, Malaysia. E-mail: howie.ceria@gmail.com 
In Malaysia, the prevalence of HIV among MSM has increased from $7.1 \%$ in 2012 to $8.9 \%$ in 2014 (Ministry of Health, 2016). There is convergence of data suggesting that YMSM are at especially high risk for HIV infection. For example, high levels of risky sexual behavior, poor levels of HIV knowledge and uptake of testing have been reported among MSM in Malaysia (Kanter et al., 2011; Lim et al., 2013) Moreover, sexual transmission accounts for the majority of new HIV cases in Malaysia (Ministry of Health, 2016), within which the proportion of young age group (13-29 years old) has increased since 2010 (Kanter et al., 2011; Lim et al., 2013).

Pervasive homophobia from the Malaysian government and religious authorities shapes policy towards YMSM, limiting funding and resources for HIV prevention programs and sex education in general (Barmania \& Aljunid, 2016). At a structural level, co-existing civil and religious law, including the colonial-era penal code 377 and Syariah (Sharia) law, criminalize male-male sexual intercourse, which may prevent YMSM from disclosing sexual behaviors and accessing HIV testing services. As a result, homosexuality, and even sex in general, remain taboo topics in Malaysia. There is, regardless, a clear need for improved sex education for Malaysian adolescents and young adults; a nationwide survey of young adults in Malaysia found that participants reported frequent misconceptions about HIV/AIDS alongside accurate knowledge, with the majority of participants' knowledge coming from mass media, such as television and newspapers, instead of formal sex education (Wong, Chin, Low, \& Jaafar, 2008).

To date, largely because of stigma and the legal implications surrounding samesex relationships, there have been no formal studies specifically investigating YMSM in Malaysia. The objective of this study is to understand the socio-cultural contexts related to HIV risk behaviors among YMSM in Malaysia, with the aim of improving HIV prevention efforts for YMSM in Malaysia.

\section{METHODS}

YMSM $(n=20)$ and local service providers (LSP; $n=4)$ were recruited for the study over a 6-week period from May to June 2015. The eligibility criteria for YMSM were: male sex at birth, aged 18-25 years, Malaysian nationality, and having had sexual intercourse with another man in the past 12 months. Four persons who were working at AIDS nongovernmental organizations (NGOs) who worked with YMSM were also recruited to the study.

YMSM were recruited with the assistance of the Pink Triangle Foundation (PTF) and Kuala Lumpur AIDS Support Society (KLASS), the only two NGOs working with MSM and HIV-positive individuals in Kuala Lumpur. Young, male clients attending the drop-in centres or an anonymous community-based testing center were screened and invited by staff to take part in the study. The study was also advertized through NGO websites, email lists, and social media. A small number of YMSM were recruited (by WB), who set up a profile in gay social networking applications Grindr and Jack'd stating clearly the research objective. LSP were recruited by faceto-face contact with staff in these organizations.

Interviews took place in a quiet office at either the NGO or the University of Malaya. Participants were informed about the background and purpose of the study, 


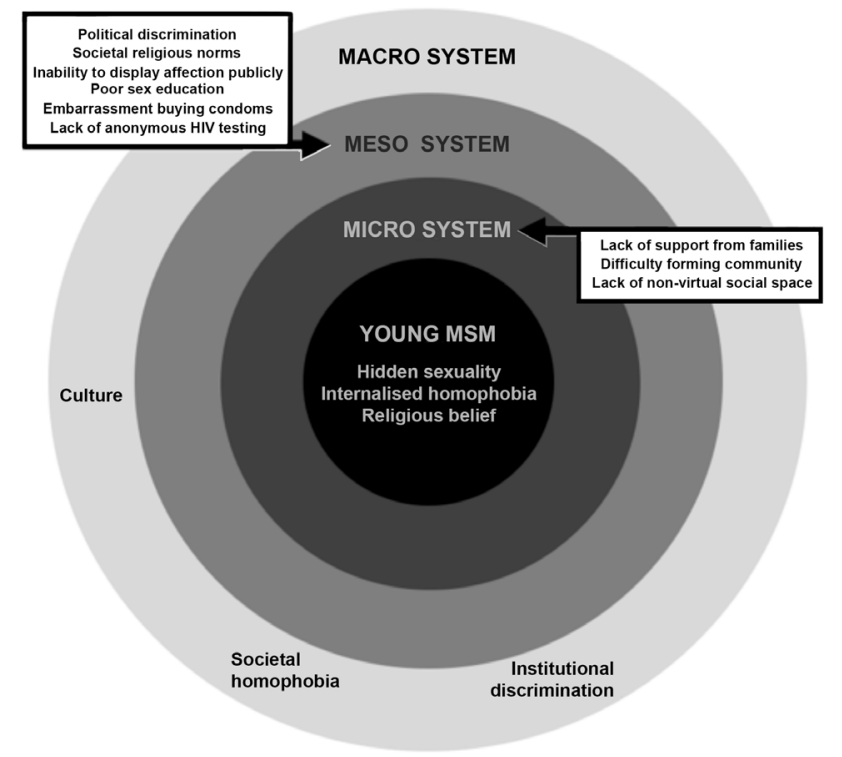

FIGURE 1. Diagrammatic representation of HIV risks among YMSM.

Adapted from Mustanski et al. (2011).

the procedure, risks and benefits of participating, before providing verbal consent to the PI. To protect their anonymity, participants were asked not to use real names throughout the study. Participants were offered RM 50 (\$12.50 US) each as compensation for their time and travel. Ethics approval was obtained from the University of Malaya and University College London.

Interviews followed a semistructured format with a pre-prepared list of questions exploring the following domains: perception and acceptance by family, friends, and society as MSM; gender role; relationships; condom use; HIV and HIV testing. Examples of questions are: How do you go looking for sexual partners?, How did you first learn about HIV? and Where do you go to get tested for HIV?

Interviews were conducted in English and audio recorded with a microphone on a password-protected laptop. Audio recordings were transcribed verbatim and deleted after transcription. Transcripts were proofread and then coded using Atlas. ti software. The codes were based on the interview domains, with new codes developed from the data on an iterative basis. Once transcripts were analyzed fully, codes were then grouped into a smaller number of code families that constituted emerging themes.

\section{FRAMEWORK}

A systematic review by Mustanksi et al. (2011) shows that HIV risk among YMSM is mediated by a range of social, cultural, political, and economic factors operating at multiple levels, from individuals (i.e., knowledge of HIV and condoms) up to the level of society (i.e., national laws governing same-sex relationships). A modified social-ecological model that incorporates these multilevel factors into a single comprehensive model was used as the conceptual framework for the study (see Figure 1). 
TABLE 1. Demographic information on participants: Age

\begin{tabular}{ll} 
Age & $n$ \\
18 & 1 \\
19 & 2 \\
20 & 2 \\
21 & 2 \\
22 & 3 \\
23 & 2 \\
24 & 4 \\
25 & 3 \\
Missing & 1 \\
Total & 20 \\
\hline
\end{tabular}

\section{RESULTS}

\section{DEMOGRAPHICS}

Demographic information on age (Table 1), ethnicity (Table 2), and occupation (Table 3) of the YMSM participants, where possible, were collected during the interviews and compiled in the tables as listed.

\section{SOCIETAL HOMOPHOBIA}

Participants reported pervasive stigma against same-sex relationships in Malaysian society; many participants used the term PLU (person/people like us) instead of gay. For this reason, almost all of the YMSM participants sought to conceal their sexuality:

\section{It's still like a taboo, you can't talk about that openly unless you're brave enough to do so ... you just can't tell anyone that you're gay. - MSM, 21years old, university student, ethnicity not obained}

Many of the participants were university students and they described public universities in Malaysia as socially conservative and oppressive. A couple of participants reported that LGBT groups had to keep undercover on campus. Several participants mentioned both the Malaysian government and media as responsible for propagating and encouraging homophobia. For example:

They [the Ministry of Education] have a guideline [to identify gay pupils] ... if they like to go to the gym, they may possibly be gay. If they're wearing V-neck then they are gay! [laughs] ... they will encourage counselors and teachers to try to identify who are the students who are gay, then identify them and send them to this camp or workshop to convert them [to heterosexuality].-LSP

\section{“DON'T ASK, DON'T TELL” WITH FAMILY AND FRIENDS}

The importance of family in driving attitudes to same-sex relationships in Malaysian society was a common theme from almost all participants. Negativity towards same-sex relationships from close family members was reported by many YMSM, putting mental stress on participants who wanted to live up to their families' expectations:

My mum told me once, "What happened [sic] if you live alone [and] there's no children to take care of you when you're old." ... sometimes the parents worries [sic] a lot. That's what creates pressure on people.-MSM, 22 years old, university student, Chinese 
TABLE 2. Demographic information on participants: Ethnicity

\begin{tabular}{lc}
\hline Ethnicity & $n$ \\
Malay & 3 \\
Chinese & 10 \\
Indian & 0 \\
Not obtained & 7 \\
Total & 20 \\
\hline
\end{tabular}

Few participants had openly come out about their sexual orientation to their families; those that did reported negative experiences. For example, a participant reported that his father sought medical opinion when the participant came out:

He was shocked ... he consulted our family doctor. The family doctor say [sic], "Why don't you bring your son to a psychologist?" So, I actually confronted them and said, "Yeah, you can bring me to a psychologist, but I'll convince the psychologist to convince you that there's nothing wrong." ...I think it takes my dad one year to digest the entire things....-MSM, 25 years old, university graduate, ethnicity not obtained

For the majority of participants who had not openly disclosed their sexuality to their parents, many felt their parents knew their sexual orientation but simply chose not to ask about it. Participants were not happy with the situation but clearly felt it was easier than telling them openly. Variations of "I think they know" were frequent, suggesting a tacit understanding but not open acceptance of the sexuality of the participants.

\section{POOR MENTAL HEALTH AS A RESULT OF A STIGMATIZED IDENTITY}

One LSP participant reflected on his own experience working with YMSM that the lack of acceptance by their families causes low self-esteem and poor mental health, leading to risky behavior:

Family is most important . . . they have to be accepted and loved . . . . [If] you don't get those feelings, you create a lot of dysfunctional coping mechanism. Including taking drugs, having risky behaviours ... why should they consider an open monogamous and accepted relationship?-LSP

Because of the societal pressure to "hide in the closet," participants reported that they were wary of friends posting items on their social media (Facebook) that might reveal their sexual orientation to the public. As a consequence, several participants described having two Facebook profiles: one for YMSM and another for their "normal" alter ego:

I think most of them now, most of them have two accounts. One account is for gays and one is for normal population.-MSM, 25 years old, university graduate, Chinese

\section{RELIGIOUS BELIEFS ON HOMOSEXUALITY}

Religion, predominantly Islam and its place with Malaysian society, was regularly mentioned as a factor influencing attitudes towards same-sex relationships. Participants who were religious, mainly Christian and Muslim, expressed internalized homophobia and significant angst as they attempted to reconcile their religious background with their sexuality: 
TABLE 3. Demographic information on participants: Occupation

\begin{tabular}{lc}
\hline Occupation & $n$ \\
Student & 13 \\
Graduate, in employment & 6 \\
Not obtained & 1 \\
Total & 20 \\
\hline
\end{tabular}

I have friends who are gay in East Malaysia... he's a very faithful Christian...he's struggling with his own [sexual] identity ... religious teachings [sic] doesn't recognize gay, is condemning gay. Gay is a sin. So it's for me that self-stigmatisations [sic] . . . they don't want to accept their own identity.-MSM, 19 years old, university student, ethnicity not obtained

The LSP participants observed that participants from a religious background strongly felt such clashes of values had an effect on behavior, leading to risky sexual behavior and risk-taking:

YMSM clients who are Malay, or who are from a very strong Catholic background for example, come in and actually tell me, "I don't want to think about HIV, I don't want to think what happens if I do risky behaviours and I expose myself to the risk of contracting HIV." —LSP

\section{LACK OF PHYSICAL SOCIAL SPACE FOR YMSM AND DIFFICULTY FINDING FRIENDS FOR SOCIAL SUPPORT}

Given the low status of MSM in Malaysian society, it was perhaps unsurprising that most participants reported having only a small circle of YMSM they knew personally, mostly from school. For almost all the interviewees, gay dating mobile phone apps were overwhelmingly the medium of choice to find new partners. Though nominally designed for socializing with and dating men, among YMSM they were mainly used for finding sexual partners:

Apps is only purely for sex, that's all. I don't believe that's for friends.-MSM, 25 years old, university student, Chinese

Apart from dating apps the other social medium mentioned was Facebook, with participants exercising caution in what they post and who they like (see above). Gay internet message boards, most of which are hosted outside of Malaysia in neighbouring Asian countries, were largely deemed to be an outdated way of meeting partners, superseded by apps and other social media.

Social interaction, however, rarely resulted from app-initiated encounters:

I find it almost impossible, personally ... to make friends on the apps, because I feel everybody goes on that just to hook up. So far, probably I've successfully made one or two friends from the apps.-MSM, 24 years old, university graduate, ethnicity not obtained

This observation of the difficulty in finding friends was shared by the LSP participants:

In Malaysia, situation is that if you have one or two MSM friends then you expect your network, your friends, from there. But if you're alone then you can't really find friends, and most of the people you meet is for sex purpose only, then you won't have a friend [laughs].-LSP 
A recurrent theme was the feeling that the societal stigma and homophobia meant that YMSM were unable to enjoy the same freedoms as heterosexual couples:

In Malaysia if you do that [same-sex relationship], out in the open, you'll probably get caught. You'll get caught and sent to the prison or something ... during my first relationship I couldn't even date my first boyfriend. And I was afraid of being judged by our people. So, I just pretended he was my mate.-MSM, 20 years old , medical student, Chinese

\section{LACK OF SEX EDUCATION AND KNOWLEDGE OF HIV/AIDS}

Participants described a lack of adequate sex education in the national school curriculum in Malaysia, and reported most of their teenage years were spent without the knowledge of safe sex and STIs. Most ended up researching and learning about HIV as a sexually-transmitted infection by themselves. Some participants were only prompted to seek sexual health advice after friends and acquaintances contracted HIV:

I do not really understand HIV at all during my earlier age . . one of my friends . . . he actually is a HIV positive. And he did tell me how he got that particular disease. So, from his experience, all those things ... I try to avoid.-MSM, 25 years old, university graduate, Malay

Where participants did report knowledge from school it was either from a purely scientific perspective in biology classes, or informally touched upon by teachers preaching abstinence, devoid of any discussion of the practicalities of safe sex and condom use:

\footnotetext{
We were taught of venereal diseases, but the way it was taught, I think, it was portrayed in a very negative manner. Like it's not something you want to have ... definitely like a negative aura to HIV/AIDS and just a sexual STDs and STIs.-MSM, 18 years old, university student, ethnicity not obtained
}

Unsurprisingly, knowledge about HIV was patchy. Though all participants knew how the virus was transmitted, other basic knowledge such as concept of the window period was lacking. A handful of participants were simply misinformed about HIV, believing that physical appearance gave an indication as to HIV status; others denied holding this view personally but reported hearing it from others.

\section{DIFFICULTY BUYING CONDOMS}

There was a spectrum of condom use reported by the participants. Participants who engaged in anal sex used condoms regularly, though many reported being frequently messaged through apps by new potential partners to engage in bareback sex.

Embarrassment purchasing condoms in shops was a common theme among participants, with a general feeling they were being judged by shop employees and fellow shoppers:

I would say Malaysia is very conservative country and ... people will assume that we [people my age] were not married. And when you buy condom ... I'll feel that [the cashier] might be judgmental on me, and that is what makes me feel embarrassed.-MSM, 23 years old, university student, Chinese

Participants described elaborate strategies, to go through the shop as quickly and discreetly as possible. Some participants were simply too embarrassed to buy them 
and asked their partner to buy them; one participant reported buying an incorrect size in haste and associating his poor experience with condoms from that. Even at PT Foundation where condoms are offered free, one participant felt too embarrassed to take them:

Even though PT foundation ... they give free [condoms] right? For me I also not dare to take. I feel like a bit weird.-MSM, 24 years old, university graduate, Chinese

\title{
CONCERN ABOUT DISCRIMINATION BY GOVERNMENT CLINICS
}

As with condom use, there was a wide variation in frequency of HIV testing, with some participants testing every few months or more frequently, and some never tested at all.

The lack of easy-to-access, anonymous, and nonjudgmental testing was a recurrent theme. Participants knew that government health centers offer free HIV testing but this was an unpopular option for several reasons. A few participants felt they would be discriminated against at these facilities, citing negative experiences from their acquaintances:

I heard a few stories about people who are lectured by the doctors to not be gay ... told them off ... [said] not have sex and "Do you realise what you're doing is wrong? I'm not going be surprised that it's going be positive today." I mean, those are the things that happen here in government hospitals here in Malaysia.-MSM, 19 years old, university student, Malay

Participants reported that the most important reason avoiding government clinics was the lack of confidentiality. A widespread concern among YMSM participants was the fact that an HIV diagnosis made in a government health center will be reported to the Ministry of Health, with lifelong negative implications, so something to be avoided at all costs. This fear was explained by one LSP participant:

\begin{abstract}
All Malaysians have this innate fear that if you get tested positive at a clinic or a hospital in Malaysia, your records will get taken down. As then you will be for some reason be hunted by the Ministry of Health [laughs]. It seems to be an innate thing and that's the kind of trouble I think a lot of MSM do avoid .... - LSP
\end{abstract}

Anonymous, community-based point-of-care testing was available from the PT Foundation, but only a fraction of participants had heard of the NGO. HIV testing was therefore perceived as a difficult and stressful experience.

\section{DISCUSSION}

The accounts of participants paint a picture of Malaysia as a deeply homophobic society, creating a sense of shame and internalized homophobia among Malaysian YMSM. In the study, some participants were unable to reconcile their sexuality with their cultural and religious background, and were unable to be open with their own families. This produced a deep sense of shame, denial, and even self-loathing within many participants. Such an environment undermines HIV prevention in this population, with evidence suggesting that perception of societal and internalized homophobia leads to increased levels of risky behavior for HIV among YMSM (Balaji et al., 2017). 
One harmful aspect of societal homophobia is the absence of sex education, particularly on gender and sexual orientation in schools. YMSM, and indeed adolescents in Malaysia in general, do not receive a comprehensive education of sex, relationships, and STIs. Embarrassment associated with purchasing condoms is clearly a barrier to their use in preventing HIV transmission, because buying condoms is often seen as a taboo.

A particularly pernicious effect of this lack of sex education results in the poor uptake of regular HIV testing by participants. In this study, YMSM expressed the wish for HIV testing to be judgment-free from the health professionals who provide it, and with minimal negative social repercussions if they were to test positive. Because most HIV testing in Malaysia does not meet these standards, most YMSM interviewed tested either infrequently or not at all, potentially missing opportunities for early diagnosis of new HIV infections.

Acceptance of homosexuality in Malaysia remains overwhelmingly low (Pew Research Center, 2013) and religious leaders in Malaysia openly voice opposition to any sexual health promotion other than abstinence (Barmania \& Aljunid, 2016). Despite this, there remains scope for the development of harm reduction arguments from a religious perspective, with Islamic scripture containing arguments that tolerating the "evil" of safe same-sex intercourse is better than exacerbating the increasing burden of HIV in Malaysia (Barmania \& Aljunid, 2016; Kamarulzaman \& Saifuddeen, 2010; Shaw, Saifi, Lim, Saifuddeen, \& Kamarulzaman, 2017). Such an approach remains a potential method of influencing Malaysian political and religious leaders in the medium-to-long-term, as an alternative to making arguments from a human rights approach.

A more effective approach at limiting new HIV infections in YMSM, given the religious and cultural environment in Malaysia, may be to frame the issue as one important public health problem. To increase access to HIV testing among YMSM in government facilities, training of HIV service providers in cultural competency and protection of confidentiality of results are needed. Having as high a proportion as possible of YMSM with HIV being diagnosed and quickly started on treatment is a public health issue for the population, and perhaps easier to achieve than arguing for more and/or improved sex education.

Improving the provision of testing also involves addressing how medical and health care staff deal with individuals who attend for testing, given negative perceptions from YMSM of their treatment by health care professionals. Tolerance of homosexuality by medical and dental students is extremely low (Jin et al., 2014), while Ministry of Health officials have expressed difficulty supporting programmes of prevention associated with illegal sexual activity (Barmania \& Aljunid, 2016). Medicalizing HIV testing in a nonjudgmental manner, and providing training to do this, may help remove cultural and religious disapproval of YMSM among Malaysian health professionals, one of the few groups that has regular and personal contact with YMSM in Malaysia. It may also represent the first step towards a professional lobby for the rights of YMSM; in a recent study by Jin et al. (2014) Malaysian health care workers reported more positive attitudes towards MSM as a result of face-to-face contact with this population.

NGOs in Malaysia, most notably PT Foundation and KLASS, perform a critical role in promoting safe sex for YMSM, including newer HIV prevention tools such as pre-exposure prophylaxis (PrEP) and post-exposure prophylaxis (PEP). However, not all of the participants had heard of these organizations or the services they offer, which include drop-in centers, safe spaces for YMSM to socialize, free condoms, 
HIV and STI testing, and counseling. This is partially a result of social stigma associated with visiting these organizations. In an attempt to reach YMSM who have not heard of the services they offer, these NGOs are currently advertising on app-based platforms, predominantly dating apps (Grindr, 2017; Online Buddies, 2017; Planet Romeo, 2017). Due to scarcity in funding however, these NGOs are unable to expand their services outside of their local geographical area. If the Ministry of Health is therefore unwilling to directly fund sexual health services for YMSM, a solution might be to instead provide the funding to NGOs that already serve this population.

There are several limitations to this study. With a few exceptions, almost all participants were recruited by the PT Foundation, forming a limited sample in respect of participants who are familiar with the PT Foundation and/or live in the Kuala Lumpur area only. Conducting interviews in English limited participation to English-speaking participants. Demographic information was not obtained from all participants and not obtained at all from LSP. Lastly, no Indian participants volunteered as they are considered a hard-to-reach population within the MSM communities in Malaysia.

\section{CONCLUSIONS}

Our findings highlighted deeply ingrained societal religious and cultural homophobia, along with widespread socially-conservative attitudes to sex, that hinder effective HIV testing and use of condoms by YMSM, and ultimately increase the risk of HIV acquisition by this population. On this basis, we suggest practical measures to improve prevention and diagnosis of HIV, by promoting anonymous testing, medicalizing HIV testing in a nonjudgmental manner and directing funding to NGOs who already provide these services to YMSM. The adoption of these recommendations has the potential to better meet the needs of Malaysian YMSM and improve the prevention of HIV transmission within this population.

\section{REFERENCES}

Balaji, A. B., Bowles, K. E., Hess, K. L., Smith, J. C., Paz-Bailey, G., \& NHBS Study Group. (2017). Association between enacted stigma and HIV-related risk behavior among MSM, National HIV Behavioral Surveillance System, 2011. AIDS and Behavior, 21, 227-237. https://doi.org/10.1007/ s10461-016-1599-z

Balaji, A. B., Bowles, K. E., Le, B. C., Paz-Bailey, G., Oster, A. M., \& NHBS Study Group. (2013). High HIV incidence and prevalence and associated factors among young MSM, 2008. AIDS (London, England), 27, 269-278. https://doi.org/10.1097/ QAD.0b013e32835ad489

Barmania, S., \& Aljunid, S. M. (2016). Navigating HIV prevention policy and Islam in Malaysia: Contention, compatibility or reconciliation? Findings from in-depth interviews among key stakeholders. BMC Public Health, 16, 524. https://doi.org/10.1186/ s12889-016-3247-y
Beyrer, C., Sullivan, P., Sanchez, J., Baral, S. D., Collins, C., Wirtz, A. L., . . . Mayer, K. (2013). The increase in global HIV epidemics in MSM. AIDS (London, England), 27, 2665-2678. https://doi.org/10.1097/01. aids.0000432449.30239.fe

Grindr. (2017, June 14). Advertise with Grindr. Retrieved June 14, 2017, from https://www. grindr.com/gay-advertising/

Jin, H., Earnshaw, V. A., Wickersham, J. A., Kamarulzaman, A., Desai, M. M., John, J., \& Altice, F. L. (2014). An assessment of health-care students' attitudes toward patients with or at high risk for HIV: Implications for education and cultural competency. AIDS Care, 26, 1223-1228. https:// doi.org/10.1080/09540121.2014.894616

Kamarulzaman, A., \& Saifuddeen, S. M. (2010). Islam and harm reduction. International Journal of Drug Policy, 21, 115-118. https:// doi.org/10.1016/j.drugpo.2009.11.003 
Kanter, J., Koh, C., Razali, K., Tai, R., Izenberg, J., Rajan, L., . . . Kamarulzaman, A. (2011). Risk behaviour and HIV prevalence among men who have sex with men in a multiethnic society: A venue-based study in Kuala Lumpur, Malaysia. International Journal of STD \& AIDS, 22, 30-37. https://doi. org/10.1258/ijsa.2010.010277

Lim, S. H., Bazazi, A. R., Sim, C., Choo, M., Altice, F. L., \& Kamarulzaman, A. (2013). High rates of unprotected anal intercourse with regular and casual partners and associated risk factors in a sample of ethnic Malay men who have sex with men (MSM) in Penang, Malaysia. Sexually Transmitted Infections, 89, 642-649. https://doi. org/10.1136/sextrans-2012-050995

Ministry of Health. (2016). Global AIDS response progress report 2016. Kuala Lumpur: Ministry of Health Malaysia.

Mustanski, B. S., Newcomb, M. E., Bois, S. N. D., Garcia, S. C., \& Grov, C. (2011). HIV in young men who have sex with men: A review of epidemiology, risk, and protector factors, and interventions. Journal of Sex Research, 48, 218-253. https://doi.org/10. 1080/00224499.2011.558645

Online Buddies. (2017). Advertise With Us I Online Buddies. Retrieved June 14, 2017, from http://www.online-buddies.com/advertising/

Pew Research Center. (2013). The global divide on homosexuality. Washington, DC: Pew Research Center. Retrieved from http://www. pewglobal.org/2013/06/04/the-global-divide-on-homosexuality/

Planet Romeo. (2017). PlanetRomeo Advertising. Retrieved June 14, 2017, from https://www. planetromeo.com/en/advertise/
Santos, G., Beck, J., Wilson, P. A., Hebert, P., Makofane, K., Pyun, T., . . Ayala, G. (2013). Homophobia as a barrier to HIV prevention service access for young men who have sex with men. Journal of Acquired Immune Deficiency Syndromes, 63, e167-e170. https:// doi.org/10.1097/QAI.0b013e318294de80

Shaw, S. A., Saifi, R., Lim, S. H., Saifuddeen, S. M., \& Kamarulzaman, A. (2017). Islam and HIV related social services in Malaysia. Journal of Religion \& Spirituality in Social Work: Social Thought, 36, 133-145. https://doi.org/10.1080/15426432.2017.1 300078

Stahlman, S., Lyons, C., Sullivan, P. S., Mayer, K. H., Hosein, S., Beyrer, C., \& Baral, S. D. (2016). HIV incidence among gay men and other men who have sex with men in 2020: Where is the epidemic heading? Sexual Health, 14, 5-17. https://doi.org/10.1071/ SH16070

Vutthikraivit, P., Lertnimitr, B., Chalardsakul, P., Imjaijitt, W., \& Piyaraj, P. (2014). Prevalence of HIV testing and associated factors among young men who have sex with men (MSM) in Bangkok, Thailand. Journal of the Medical Association of Thailand, 97, S207-S214.

World Health Organization. (2015). HIV and young men who have sex with men. Geneva, Switzerland: World Health Organization. Retrieved from http://www.who.int/ hiv/pub/toolkits/hiv-young-msm/en/

Wong, L.-P., Chin, C.-K.L., Low, W.-Y., \& Jaafar, N. (2008). HIV/AIDS-related knowledge among Malaysian young adults: Findings from a nationwide survey. Journal of the International AIDS Society, 10, 148. https:// doi.org/10.1186/1758-2652-10-6-148 